\title{
Organização do Espaço e do Tempo na Inclusão de Sujeitos com Autismo
}

\author{
Catia Giaconi' \\ Maria Beatriz Rodrigues" \\ 'Universidade de Macerata, Macerata - Itália \\ "Centro Pedagogico PROF (Fillotrano) - Itália
}

RESUMO - Organização do Espaço e do Tempo na Inclusão de Sujeitos com Autismo. Propomos uma reflexão integradora entre especificidades da síndrome do autismo e possíveis linhas de ação para a inclusão escolar. Discutimos pressupostos históricos e normativos, indicadores de boas práticas, que buscam conjugar qualidade com escolhas pedagógicas. Enfatizamos uma série de novas atenções profissionais, principalmente no que se refere à contínua investigação sobre hipóteses etiológicas do autismo, diagnóstico precoce, assim como prontidão e pluralidade das intervenções educativas e didáticas, que favorecem projetos de inclusão escolar. Analisamos as principais abordagens sobre o autismo, recolhendo elementos essenciais para uma proposta, ou linhas-guia, de inclusão de sujeitos com autismo na escola.

Palavras-chave: Autismo. Inclusão Escolar. Organização Espaço e Tempo.

ABSTRACT - Organization of Time and Space for the Inclusion of Subjects with Autism. We propose an integrative reflection between considerations on the specificity of the autism syndrome and possible guidelines for their inclusion at school. We discussed historic and normative assumptions, indicators of good practices that aim at the combination of quality and pedagogical choices. There is an exploration of new professional care, mainly referring to the continuous investigation on etiological hypotheses, early diagnosis, as well as timely and multiplicity of the educational and didactic interventions in autism that favor school inclusion projects We analyze the major approaches on autism, gathering essential elements for a proposal, or guidelines for the inclusion of subjects with autism at school.

Keywords: Autism. School Inclusion. Organization of Time and Space.

Educação \& Realidade, Porto Alegre, v. 39, n. 3, p. 687-705, jul./set. 2014.

Disponível em: <http://www.ufrgs.br/edu_realidade> 
Organização do Espaço e do Tempo na Inclusão de Sujeitos com Autismo

\section{Introdução}

Em consonância com as numerosas investigações sobre a efetiva inclusão escolar e com os processos cognitivos dos sujeitos com Transtornos Globais do Desenvolvimento (TGD), propomos neste texto uma reflexão posicionada na intersecção entre as considerações quanto à $e s-$ pecificidade desta síndrome e as possíveis linhas-guia para a integração escolar ${ }^{1}$ de sujeitos com autismo. Trata-se de um exercício de pesquisa que se integra com outro exercício mais amplo, de descrição e teorização de um sistema de critérios de qualidade de inclusão escolar, tema de muitos estudos e de rica discussão científica² ${ }^{2}$.

$\mathrm{O}$ texto toma forma e difunde-se em uma dupla perspectiva. De um lado, exploramos pressupostos normativos e históricos partindo do estado da arte (Ianes; Tortello, 1999) da inclusão de pessoas com deficiência nos contextos escolar e laboral (Campanini, 2005; Lascioli; Menegoi, 2006), nos níveis nacional e internacional. De outro lado, apreciamos tentativas dirigidas à identificação de um sistema de indicadores (Canevaro, 1999; Cottini, 2004; D’Alonzo, 2006; Crispiani; Giaconi, 2007) e de boas práticas (Canevaro; Ianes, 2002), que possam integrar qualidade com uma seleção de vias de qualidade, operadas por meio de um filtro pedagógico de plataformas teóricas, inclusive de origem empresarial (Crispiani; Giaconi, 2007).

Nessa direção, pensamos ser importante conduzir a análise e o planejamento inerentes aos temas do autismo e da inclusão por pelo menos três considerações que dão sentido a uma incessante e repetida exploração destes domínios conceituais e que dizem respeito:

1. ao ulterior e ao contínuo aprofundamento conceitual originário das teorias de referência e das pesquisas;

2. à necessária passagem do tempo, que coloca um adequado intervalo entre as teorias e as consequentes reflexões;

3. à fértil comparação com as opiniões ou avaliações de profissionais (pedagogos, professores, formadores, terapeutas, famílias, etc.) envolvidos no campo (D’Alonzo; Ianes, 2007) .

Este artigo apoia-se em uma série de novas atenções profissionais para a contínua investigação sobre hipóteses etiológicas, para a avaliação e o diagnóstico precoce e prontidão nas intervenções, para a pluralidade das intervenções educativas e didáticas, para os projetos de integração na escola e no trabalho, para o autista adolescente em estreita conexão com aspectos de sexualidade (Caretto, 2005; Aliata, 2006; Lawson, 2006), para a condição adulta das pessoas com deficiência (Montobbio; Lepri, 2000; Morgan, 2003) e para os cuidados por parte da família (Crispiani, 2008).

As ações profissionais da educação especial orientam-se e qualificam-se nas seguintes direções: 
1. A prevenção, ou seja, um conjunto de cuidados e intervenções sobre o indivíduo e o ambiente, para:

- Impedir o aparecimento de distúrbios ou o de problemas (prevenção primária);

- Estabelecer a individuação precoce de casos a risco de um determinado distúrbio, que já deu sinais de manifestação, para uma eventual intervenção tempestiva (prevenção secundária);

- Evitar o agravamento ou o surgimento de complicações, efeitos colaterais ou a estabilização de um estado crônico de um problema já manifestado (prevenção terciária) (Marcelli; Braconnier, 2006) ${ }^{4}$.

A ação preventiva pode ser dirigida a um grupo de pessoas sem distinção (prevenção universal), a grupos específicos em situação de risco $^{5}$ (prevenção seletiva) ou a grupos que manifestam o problema ou distúrbio (prevenção específica) ${ }^{6}$.

2. O diagnóstico especial, com particular atenção às intervenções plurais pedagógicas (Crispiani; Giaconi, 2008), ao diagnóstico precoce, ao diagnóstico funcional, à avaliação pedagógica contínua, etc.

3. O tratamento educativo, na forma ecológica e multimodal ${ }^{7}$, sobre toda a personalidade humana e sobre deficiências específicas do caso, mediante uma pluralidade de estratégias de intervenção, auxílios, treinamento, etc.

4. A integração escolar e laboral, portanto, a valorização de projetos dirigidos à qualidade de vida das pessoas com deficiência (criança, adolescente, adulto e idoso).

5. A avaliação/controle dos percursos projetados.

6. A comunicação e o planejamento conjunto com a família, com possíveis percursos de formação de pais (parent training).

Essas fases de ação pedagógica profissional são de grande relevância no caso de síndrome do autismo e manifestam sua urgência em todas as condições de vida do sujeito autista, para o qual é projetado um conjunto de ações diagnósticas (screenings, diagnóstico precoce, diagnóstico funcional, etc.) e educativas que se reúnem no paradigma do cuidado global, ou seja, da abordagem ecológica.

Com relação ao screening e ao diagnóstico precoce, por exemplo, vários autores (Filipek, 1999; Siegel, 1998; Schopler; Reichler; Renner, 1998; Skuse, 2004; Berument et al., 1999; entre outros) evidenciam o grande peso dessas ações para a rápida ativação de intervenções adequadas e eficazes. Nesse propósito, Siegel (1998) enfatiza a necessidade de associar um primeiro nível de screening, que inclui a identificação precoce de um possível desenvolvimento clínico patológico em crianças $a$ risco, a outro posterior, um segundo nível de screening, específico à identificação de crianças com risco de autismo.

Educação \& Realidade, Porto Alegre, v. 39, n. 3, p. 687-705, jul./set. 2014.

Disponível em: <http://www.ufrgs.br/edu_realidade> 
Com relação à intervenção educativa, especificamente à adaptação necessária a cada processo vital biológico e psicológico, revela-se de grande relevo para a síndrome do autismo, que talvez resulte como a única na qual as dificuldades de adaptação requerem um processo de integração preventiva, anterior à ação de inclusão propriamente dita. Além disso, a natureza generalizada ou pervasiva da síndrome determina uma condição de ampla desordem funcional, com evidente comprometimento neurobiológico difuso, tal que o sujeito é tratado quase sempre por toda a vida e vale, para ele, o princípio de tratar sem curar.

Continuando nessa direção, bem expresso no DSM-IV-TR (2002) e na literatura especializada, a perspectiva de melhora da qualidade de vida é colocada sob-refletores, principalmente em dois âmbitos de ganhos formativos:

1. Melhora de algumas áreas funcionais (perceptivas, comunicativas, intelectuais, relacionais, etc.) e de suas coordenações, ou níveis organizativos, nas quais se evidencia a função cognitiva global;

2. Melhora da adaptação a diversos ambientes de vida, relacionada à idade do sujeito, condição primária para a qualidade de sua vida.

O processo adaptativo torna relevantes cinco contextos especialmente envolvidos em sua consecução:

- família;

- escola;

- centros especializados (reabilitativos, sociais, comunidades);

- locais de trabalho;

- locais de lazer.

A esses compete, em razão da especificidade da síndrome da qual tratamos, ativar ações diretas e indiretas para consentir a necessária liberação de processos que permitam a pessoa autista de viver suficientemente a presença nas situações. Sempre considerando a gravidade do caso, isso é aceitável quando:

- se previnem ou atenuam as crises reativas;

- o sujeito compreende as principais dinâmicas físicas e relacionais expressas no ambiente;

- evitam-se ou atenuam-se os estados de sofrimento.

Em razão do acima exposto, após uma breve apresentação da $d i$ versidade especial dos sujeitos com síndrome do autismo, com a eficaz imagem de Peeters do sofrimento das funções espaciais e temporais, continuaremos com o delineamento de algumas linhas de ação para o planejamento e estruturação do espaço e do tempo nos contextos escolares. 


\section{O Autismo: uma pesquisa marcada pela complexidade}

Grandes contribuições sobre o autismo são frutos de trabalhos científicos de proveniências diversas (biologia, genética, neurologia, psicologia, pedagogia, etc.), em favor de uma abordagem complexa, de amplo espectro, que, exercitada na vasta pesquisa etiológica e clínica, assume a ideia compartilhada de que a síndrome se apresenta de forma variada, seja por proveniência etiológica, seja por quadro sindrômico (sintomas primários, secundários, derivados e falsos sintomas).

Com referência a esses conhecimentos, concordamos com vários autores (Canevaro, 1999; Filipek, 1999; Sinpia, 2005; Valenti, 2008), que assumem uma perspectiva plural inerente à difícil ou impossível delimitação da síndrome do autismo, a partir da própria definição, da ampla fenomenologia dos autismos (Canevaro, 2000) a alto perfil individual, da diversa progressão de níveis de gravidade (de leve a gravíssimo) e das formas de comorbidade com outros distúrbios, que, na complexidade, dão sentido às noções de espectro e de continum do autismo.

É importante também refletir que, com referência às tendências gerais epidemiológicas encontradas nas premissas do DSM-IV, observa-se um decréscimo das monopatologias a favor da pluripatologia, portanto a forma específica teria sua presença reduzida. Por outro lado, a tendência atual, que denominamos plásticos (Crispiani, 2002), própria das orientações das ciências cognitivas, reconduz para dentro do espectro autístico todos os casos de distúrbios da comunicação (verbal e não verbal), acrescendo e dilatando o número dos casos em questão ${ }^{8}$.

Esta visão lança uma nova luz ao complexo cenário da investigação etiológica, no qual a pesquisa sobre a causa primeira deixa espaço a um processo de retroação etiológica progressiva, cuja perspectiva não é inteiramente percebida. No específico, Frith $(1998$, p. 101), a propósito da síndrome do autismo, recorre ao conceito de corrente causal para indicar os diversos níveis de configuração da causa da patologia, da condição de risco, que pode ser mais ou menos clara, nos quais precipita uma situação fisiológica, de ligação ao nível da manifestação, ou seja, ao dano.

O plafond científico de referência, que sublinha o distúrbio do autismo como distúrbio qualitativo, concorda com a fórmula de Peeters (2000), para o qual a criança autista apresenta-se como especialmente especial ${ }^{9}$. Tal abordagem vai da abordagem psicoeducativa de Peeters (1999; 2000) à proposta mentalista de autores como Baron-Cohen; Hadwin; Howlin, 1999 e Frith (1995; 1998), ou seja, no sentido genérico, posições cognitivistas e neurocognitivas.

Estas linhas de pesquisa permitem a pertinente indagação sobre uma tríade de áreas disfuncionais essenciais, primariamente afetadas, entre os primeiros três anos de vida, ou seja, a comunicação, a interação social e a esfera de interesses.

Educação \& Realidade, Porto Alegre, v. 39, n. 3, p. 687-705, jul./set. 2014.

Disponível em: <http://www.ufrgs.br/edu_realidade> 
Organização do Espaço e do Tempo na Inclusão de Sujeitos com Autismo

Na literatura mentalista, é aprofundado o comprometimento nos sujeitos autistas, do que Frith (1998) define teoria da mente ou a capacidade de metarepresentação, ou seja, a capacidade de representar-se ou conhecer o próprio estado mental ${ }^{10}$ e de outras pessoas, fundamental para atribuir significado ao comportamento e poder prevê-lo. Segundo esses estudos ${ }^{11}$, os sujeitos autistas demonstram uma específica dificuldade na atribuição de crenças ou falsas crenças às outras pessoas, considerada um tipo de estado mental, com consequente fixidez do pensamento frente aos eventos, objetos reais e concretos, que definiremos como pensamento real.

Nessa mesma linha, Baron-Cohen (1997) introduz o conceito de cegueira mental (mind blindness) para explicar a significativa dificuldade dos indivíduos autistas para decifrar os olhos e as expressões faciais dos outros e, dessa forma, seus estados emocionais e relacionais. A esse propósito, adicionam-se investigações dos anos 1990, que colocam em evidência como nas crianças com autismo existe um distúrbio essencial na atenção compartilhada, ou seja, na capacidade de orientar a atenção a um evento/objeto, em paralelo e de forma organizada, com uma outra pessoa. A condição autista geral resulta em sobrecarga cognitiva e social, com uma específica carência na integração e na organização das várias informações em um nível unitário e central, que garantiria uma visão orgânica e do todo, conhecida como distúrbio de coerência central e que explicaria uma série de características cognitivas (pensamento em detalhes, pensamento real, etc.), que ilustraremos a seguir (Figura 1. Pensamento autista: indicadores e descritores).

Em proximidade com a síndrome do autismo e, em particular, com a linha teórica da teoria da mente, insere-se o fenômeno dos "neurônios-espelhos" (Rizzolatti; Sinigallia, 2006; Crispiani; Giaconi, 2006; Rizzolatti; Fabri; Destro, 2008; Rizzolatti; Vozza, 2008), sistema que se ativa não somente quando se cumpre uma ação, mas também quando se vê o cumprimento de uma ação ou se sente um rumor associável diretamente a uma ação. A teoria da mente, assim como o sistema a espelho consistiriam em exercitar funções, como a representação mental, a imitação, a predição, o jogo de faz-de-conta, o jogo simbólico, etc., cuja matriz está na imaginação e é reconhecida por Baron-Cohen no sistema ToMM ${ }^{12}$, módulo neural que ocupa o mesmo espaço dos neurônios-espelho. Isso é confirmado por Marcus (2004), que sustenta que o cérebro dos animais e do homem exibem um sistema especial de neurônios-espelho que poderiam constituir requisitos para a imitação, uma função que no homem aparece precocemente e que é motivo para o desenvolvimento e a estabilização da cultura e dá origem à capacidade de agir como sujeitos individuais, mas também sociais. Marcus (2004, p. 32) ainda afirma "Formas mais ou menos complicadas de imitação, de aprendizagem, de comunicação gestual e verbal encontram, na realidade, uma verificação pontual na ativação de específicos circuitos-espelho".

692 Educação \& Realidade, Porto Alegre, v. 39, n. 3, p. 687-705, jul./set. 2014 Disponível em: <http://www.ufrgs.br/edu_realidade> 
Os estudos sobre os neurônios-espelho enfatizam que suas funções centrais são as de interpretar o escopo das ações percebidas (vistas e escutadas), representar os seus sentidos para, então, serem capazes de reproduzi-las, exercício que aparece fortemente prejudicado na síndrome autista, como já referido por diversas abordagens teóricas (cognitivos, mentalistas), e em investigações que ganharam importância desde os anos 2000 e que exploram a conexão entre distúrbios autistas e disfunções do sistema espelho, como as de Williams et al. (2001); Theoret et al. (2005); Villalobos; Mizuno; Dahl (2005); Rizzolatti; Sinigallia (2006), entre outros.

A função central desempenhada pela imitação, na compreensão e reprodução da linguagem e do movimento, torna particularmente interessante a consideração dos neurônios-espelho em relação à síndrome autista, por apresentar um distúrbio específico da função imitativa. A escassa atividade dos neurônios-espelho, ou a ausência dela, tem sido considerada a causa de atraso nas aprendizagens imitativas motoras e linguísticas, que é conhecido como a condição do autismo de apresentar distúrbios relacionados com a comunicação e com a motricidade no sentido lato. Investigações clínicas revelaram inclusive traços comportamentais idênticos na área motora e na linguística do sujeito com autismo: estereotipia, ecolalia, descoordenação, tendência ao caos, afinalismo, etc.

Esta breve resenha permite observar a total diversidade ou especificidade do autismo, em que, segundo Peeters (1994), "O significado do autismo é o próprio autismo".

As principais funções biopsíquicas e operativas do autismo, como traço primário de diversidade, são:

- as coordenações motoras (dispraxias, distúrbios das sequências motoras, distúrbios das sinestesias, distúrbios dos esquemas motores sequenciais, das seleções ideomotoras, distúrbios psicomotores, relacionados à velocidade, frequente dislateralidade, etc.);

- as coordenações perceptivas (desordens espaço-temporais, dispraxias perceptivas, percepções em caos/detalhes, distúrbios da coordenação visual e da percepção de movimentos, de sequências perceptivas, da integração perceptiva, etc.);

- o controle da emotividade e da afetividade (desorganização da reatividade, controle escasso, descontinuidade-fixidez, etc.);

- a adaptação (distúrbios de adaptação a pessoas, ambientes, jogos, trabalhos, linguagens, etc.);

- o pensamento (desordens da memória, das estruturas temporais, das conexões lógicas, distúrbios da imaginação, pensamento em caos/detalhes, etc.);

- a comunicação (desordens da comunicação integrada, descontinuidade, etc.); 
- as funções linguísticas (desordem fonética, fonológica, atraso da palavra, desordem sintática, semântica, etc.);

- a capacidade relacional;

- a ação autônoma;

- etc;

Mesmo muitas vezes associadas a déficits/diminuição, tais funções aparecem descoordenadas, não orgânicas, tendendo ao caos, descontextualizadas, não generalizadas, etc. O estado de déficit, expresso como retardo mental, déficit linguístico (dislalia, etc.), simbólicos, entre outros, pode ser considerado comorbidade primária ou derivações secundárias do estado primário de desordem ou diversidade.

\section{Os Estilos de Pensamento nas Pessoas com Autismo}

Em estreita conexão com as perspectivas cognitivas e mentalistas, vistas anteriormente, e com a abordagem psicoeducativa de Peeters (2000), retomamos a forte imagem peetersiana da teoria do iceberg, tentando ir além dos sintomas, da ponta do iceberg, para penetrar no corpo submerso.

Nesse sentido, parece relevante considerar os traços de pensamento do autismo, ou seja, características intelectuais e comportamentais que acompanham em várias medidas o agir do autista na direção de seu perfil cognitivo individual (Crispiani, 2004; Giaconi, 2004). Tais marcadores sindrômicos primários podem ser individualizados nos seguintes indicadores e descritores ${ }^{13}$ (Figura 1. Pensamento do Autista: Indicadores e Descritores).

\section{Figura 1 - O Pensamento no Autismo: indicadores e descritores}

\begin{tabular}{|c|c|}
\hline $\begin{array}{l}\text { Pensamento realístico } \\
\text { (ausência de imaginação) }\end{array}$ & $\begin{array}{l}\text { Atitudes de associações concretas; rígida associação } \\
\text { de significados primários a objetos e eventos; } \\
\text { ausência de imaginação e generalização. }\end{array}$ \\
\hline Pensamento em detalhes ${ }^{14}$ & $\begin{array}{l}\text { Tendência a concentrar a atenção sobre detalhes; } \\
\text { "hiperseletividade" das partes em vez do contexto } \\
\text { ou do geral. }\end{array}$ \\
\hline Pensamento caótico & $\begin{array}{l}\text { Caótica, descoordenada e confusa percepção } \\
\text { e compreensão dos contextos, das mensagens } \\
\text { verbais, dos rostos e das suas expressões, das } \\
\text { dinâmicas relacionais, das regras e das mudanças } \\
\text { imprevisíveis. }\end{array}$ \\
\hline Pensamento visual $^{15}$ & $\begin{array}{l}\text { Preferência por uma modalidade de trabalho mental } \\
\text { "visual", icônica, por imagens. }\end{array}$ \\
\hline Ecolalia & Repetição literal de palavras e frases. \\
\hline Comportamento eco & $\begin{array}{l}\text { Condutas repetitivas, rituais, insistência frente a } \\
\text { situações pouco claras, ofuscadas ou incertas. }\end{array}$ \\
\hline Pensamento agressivo & $\begin{array}{l}\text { Tendência a recorrer a crises agressivas para } \\
\text { demonstrar aprópria contrariedadecomo contexto, } \\
\text { com os desejos não satisfeitos, expectativas não } \\
\text { correspondidas, necessidades não satisfeitas. }\end{array}$ \\
\hline
\end{tabular}


Giaconi; Rodrigues

\begin{tabular}{|l|l|}
\hline Pensamento bizarro & $\begin{array}{l}\text { Propensão a recorrer a comportamentos bizarros } \\
\text { para demonstrar a própria contrariedade com o } \\
\text { contexto, desejos não satisfeitos, expectativas não } \\
\text { correspondidas, necessidades não satisfeitas. }\end{array}$ \\
\hline Cegueira mental/social & $\begin{array}{l}\text { Escassa compreensão do mundo, subjetivo e } \\
\text { objetivo; incapacidade de decifrar os olhos e } \\
\text { expressões faciais dos outros, o estado emocional } \\
\text { e relacional. }\end{array}$ \\
\hline
\end{tabular}

Fonte: Crispiani; Giaconi (2002).

Juntamente com o provável retardo mental, ou com a condição de normalidade intelectual, a função geral indicada como pensamento ${ }^{16}$ trai traços qualitativamente diversos (desordenados, desorganizados), mais do que deficitários ou diminuídos. Esses, evidentemente, tornam improvável, ou carregado de descontinuidade e sofrimento, o processo de adaptação às situações e induzem condutas desadaptadas de vários tipos:

- Desconfiança, medo, recusa/rejeição, evitação, fechamento;

- Respostas bizarras, agressivas;

- Ritualismo e estereotipias motoras, perceptivas, verbais, etc.;

- Rejeição a mudanças de qualquer tipo;

- Comunicação imprópria;

- Condutas obsessivas.

A identificação desses problemas envolvidos na compreensão das situações e na previsão dos eventos, associados à adaptação do sujeito autista nos ambientes escolares ou sociais, requer uma melhor definição do sofrimento dos sujeitos autistas no espaço e no tempo.

A literatura científica de referência, além de histórias de autistas dotados, evidencia como os sujeitos autistas sofrem a organização do espaço e do tempo. No primeiro caso, demonstram dificuldades de orientação, de movimento autônomo nos ambientes e de distinção e associação dos vários espaços às suas funções. No segundo caso, demonstram dificuldades em perceber o passar do tempo, de representar e evocar, em ordem, o passado e prever o futuro próximo.

A explicação científica e clínica para tal condição reside no distúrbio de decognição, ou seja, na pervasiva desorganização cognitiva e na dificuldade de imaginaçãa ${ }^{17}$, que torna difícil pensar em coisas, imagens ou eventos que não sejam imediatamente presentes.

A despeito da notória solidariedade e reciprocidade do espaço e do tempo em disputarem a eficácia e a eficiência de todo o comportamento (do movimento à percepção, das emoções ao pensamento, da linguagem à socialização), na representação/organização do tempo reside um elevado índice de dificuldade com relação à representação/organização do espaço.

Nesse sentido, podemos ler nas páginas do texto de Haddon (2003, p. 180) sobre o maior sofrimento do tempo em relação ao espaço nos sujeitos autistas:

Educação \& Realidade, Porto Alegre, v. 39, n. 3, p. 687-705, jul./set. 2014.

Disponível em: <http://www.ufrgs.br/edu_realidade> 
O tempo não é como o espaço. E quando deixamos alguma coisa em algum lugar, por exemplo, um goniômetro ou um biscoito, em nossa cabeça desenhamos um mapa do ponto onde se encontram, mas mesmo se não tivermos um mapa não importa porque o objeto continuará lá. Um mapa é a representação de alguma coisa que existe realmente, então será possível reencontrar o goniômetro e o biscoito.

O espaço em relação ao tempo presta-se mais à tradução em imagens (fotografias, desenhos, modelos, etc.), favorecendo uma estimulação icônica e verbal, auxiliando os que, como os autistas, preferem formas de pensamento visual. Ao contrário, o tempo é mais difícil de ser representado e de ser compreendido, por suas características de abstração e fugacidade que, com frequência, conduzem o sujeito autista a perder-se no tempo, como o protagonista do romance de Haddon:

[...] um horário é um mapa do tempo, só que se não temos um horário o tempo não permanece onde está, como a escada, o jardim e a rua para ir à escola [...] isto significa que o tempo é um mistério e não é tangível [...] perder-se no tempo é como perder-se no deserto, só que o deserto não pode ser visto porque não é um objeto [...]. É por isso que gosto dos horários, porque fazem com que não te percas no tempo (Haddon, 2003, p. 180).

O tempo, então, deve ser também marcado visualmente (por exemplo, por meio de relógio mural com fotos, desenhos, etc.), em sua sucessão, indicando sua passagem, segundo noções do tipo antes-depois, antes de, depois de, intervalo ou duração.

Tais considerações permitem ainda uma vez qualificar o distúrbio autista como dispraxia sequencial, ou seja, condição de desorganizada executividade de sequências de ações nos contextos espaciais e temporais. Estabelece-se o seguinte círculo vicioso que vê uma recíproca alteração entre as funções temporal e espacial e a velocidade executiva: se realmente são alteradas a temporalidade e a espacialidade, altera-se a velocidade executiva e, por outro lado, altera-se a velocidade de execução que induz à disfunção a temporalidade e a espacialidade (Crispiani; Giaconi, 2008, p. 45).

Para este sujeito, parece significativa a imagem do radar desregulado, como lugar de distorção ou desordem qualitativa dos processos perceptivos, organizativos, sequenciais, etc., ou seja, dos processos cognitivos que diminuem nas dimensões de tempo e espaço e que são sensíveis à velocidade executiva e as suas mudanças.

Em tal regime cognitivo, regulado de modo desorganizado - distúrbio cognitivo qualitativo - que nós definimos decognição, ou seja, o conjunto de desapercepções ou descompreensões frente à realidade constitui motivo de desadaptação e gera o sentimento da expectativa traída e possíveis reações de crise, sintetizáveis da seguinte forma: 
- Viscosidade, repetitividade, ritualidade, resistência à mudança;

- Crises motoras, hipercinéticas, vocais;

- Crises emocionais com ou sem condutas autolesionistas ou agressivas;

- Fuga;

- Resistência, passividade, ausência;

- Condutas imprevisíveis, finalísticas, bizarras; entre outras.

Pela propensão ao desenvolvimento desse tipo de reações, o processo de inclusão na escola de um sujeito com autismo é considerado particularmente problemático. O difícil trabalho adaptativo requerido é ulteriormente dificultado por comprometimentos comunicativos, relacionais e, sobretudo, imaginativos dos quais o sujeito é portador. Esses distúrbios facilmente dão lugar a condutas de recusa e rejeição, que Peeters chama de estratégias de defesa, como as acima listadas. O planejamento de linhas-guia para a inclusão escolar de sujeitos com autismo não pode excluir uma intencional atenção à estruturação dos espaços e dos tempos, como propomos a seguir.

\section{Adaptar Antes de Incluir}

Colocar o sujeito autista em condições de desadaptação é motivo de sofrimento. Por suas características cognitivas, principalmente os processos executivos de percepção, compreensão, controle emocional, comunicação, entre outros, pelo efeito dos seus distúrbios nos processos sequenciais e nas sinestesias ${ }^{18}$, pela fragilidade emocional e relacional que o distingue, o aluno autista necessita de um processo progressivo de inclusão na escola, precedido por ações conscientes e miradas na adaptação.

Trata-se, em relação a essa síndrome, diversamente de tantas outras, de adaptar antes de incluir, projetando e direcionando uma série de cuidados e ações que permitam, ao momento oportuno e progressivamente, favorecer primeiro a presença e depois as melhores e possíveis formas de participação na escola, na classe e nas atividades.

Com clara referência ao trabalho pioneiro de Schopler et al. (1988; 1998; 2001), mas antes dele às intuições de Itard $(1998)^{19}$, o evento da escolarização e as sucessivas passagens de ambiente são projetadas como ações educativas fundamentais, como formas de criar modalidades adaptativas para cada aspecto, dos físicos, às pessoas e às atividades, e torná-los acessíveis a autonomia e a orientações que, de outra forma, resultariam em obstáculos à adaptação e à participação. Embora para nós tudo isso seja fácil - assinala Peeters (2000) - para eles é muito difícil; devem ser prevenidos os momentos de descompressão e de desorientação, agindo sobre o contexto e sobre as pessoas (docentes e outros), a ação indireta, juntamente ao trabalho educativo e de controle adaptativo sobre o sujeito, a ação direta.

Educação \& Realidade, Porto Alegre, v. 39, n. 3, p. 687-705, jul./set. 2014.

Disponível em: <http://www.ufrgs.br/edu_realidade> 
Antes do início do ano letivo, ativam-se momentos de experiência e conhecimento dos ambientes, pessoas e atividades, de modo que a escola se apresente como um ambiente que fala por si só, no qual estão presentes materiais que falam por si mesmos e atividades que falam por si mesmas. Esse processo de adaptação evita a constante solicitação do(a) professor(a) durante as aulas e, além disso, os elementos do ambiente tornam-se facilmente (e visualmente) compreensíveis.

Exercitam-se ações adaptativas preventivas em relação a

- mudanças;

- ambientes externos;

- ambientes internos;

- pessoas e rostos;

- percursos;

- sequências de ações;

- instruções;

- símbolos e códigos;

Tal processo adaptativo preventivo exercita-se mediante antecipações relativas a

- imagens e ícones;

- gestualidade;

- mensagens verbais;

- trabalho sobre realismo verbal;

- predições;

- narrativas;

- ações graduais;

\section{Linhas-Guia para a Adaptação Escolar: uma proposta}

Coerente com indicações de alguns programas educativos, como o $\mathrm{TEACCH}^{20}$, e do quanto evidenciado com relação ao sofrimento dos sujeitos autistas com a organização espaço-temporal, podemos individuar duas macro-linhas de intervenção:

1. organizar de modo visual (com objetos, fotos, imagens), previsível, estável e reconhecível o espaço escolar: escola em geral, acesso (entrada e saída), aula, banheiro, refeitório, ginásio, jardim, disposição dos móveis e dos materiais, etc.;

2. organizar de modo visual, previsível, estável e reconhecível o tempo escolar: cadência temporal das lições do turno, calendário da semana, do mês (por exemplo, relógios murais diários, cartazes semanais, cartazes mensais).

Os ambientes e materiais devem, portanto, apresentar-se por si mesmos, ou seja, ser estruturados de tal modo que facilitem a compre- 
ensão da ordem e os significados ou atividades associadas aos vários espaços e materiais. Na mesma direção, o tempo deve ser projetado e representado visualmente para que a criança/adolescente com autismo possa predizer e entender o que está acontecendo, o que aconteceu e o que acontecerá.

A proposta de estruturação de uma escola, como aqui delineada, fundamenta-se em linhas-guia que visam colocar os sujeitos com autismo na condição de situar-se mais facilmente em um espaço e um tempo previsíveis, ou seja, de terem consciência de onde se encontram, com quem e o que está para acontecer/fazer.

Comecemos pelo espaço de acesso à escola. O sujeito necessita de pontos de referência visíveis e concretos já no ingresso da escola, que podem ser organizados de modo claro, em torno de uma série de objetos (uma estátua, um aquário, um vaso, etc.), ou de elementos sonoros (por exemplo, uma campainha na porta de entrada).

Passemos às orientações quanto ao edifício da escola, que pode ser organizado com linhas-guia ou faixas coloridas ao longo do corredor, para indicar os diversos percursos que conduzem aos vários ambientes (por exemplo, linha verde conduz à sala de aula, linha amarela ao refeitório e assim por diante). Estes espaços e suas funções devem ser antecipados com objetos ou imagens colocadas na porta de entrada, que demonstrem as respectivas atividades (como um prato na porta do refeitório).

Com relação à organização da sala de aula, o programa TEACCH propõe utilizar espaços e mobiliário claros, delimitados, estáveis e fixos para o desenvolvimento de atividades de trabalho, de lazer, merenda e outras. Os ambientes de trabalho são selecionados tendo em vista a presença de menos elementos, para que não provoquem sobrecarga perceptiva (muitos cartazes, janelas, cores, etc.). O espaço de trabalho é estruturado com a delimitação de um ângulo da sala de aula, por meio de duas estantes nos lados opostos, com uma escrivaninha central girada em direção à parede. A disposição dos móveis, além de delimitar o espaço, segue uma indicação do procedimento para o desenvolvimento das atividades: na prateleira da esquerda são colocadas as atividades a serem realizadas, na da direita as atividades concluídas. Nesta fase de projeto, os materiais também devem ser de fácil acesso, antecipados com imagens e cores, para compensar as eventuais dificuldades de compreensão.

Para a cadência e sucessão do tempo na escola, pode-se utilizar um cartaz/relógio mural, constituído de uma sequência de objetos, fotos, imagens, palavras ${ }^{21}$, ordenadas de cima para baixo, no caso do cartaz, ou em sentido horário, no caso de relógio mural, indicando a sequência das ações a serem realizadas. No início de cada atividade, a criança/adolescente com autismo é convidada a mover o ponteiro até a atividade que deve realizar ou a colar no cartaz a imagem da tarefa a ser realizada.

Educação \& Realidade, Porto Alegre, v. 39, n. 3, p. 687-705, jul./set. 2014.

Disponível em: <http://www.ufrgs.br/edu_realidade> 
Estas simples indicações visam favorecer e chamar a atenção de professores ou de outros profissionais da escola, para atentar à predisposição de ambientes e tempos escolares, à luz dos problemas de adaptação do caso e de suas necessidades especiais de previsibilidade, de orientação imediata, estabilidade, fácil compreensão da situação e da passagem do tempo.

Recebido em 14 de março de 2014 Aprovado em 13 de maio de 2014

\section{Notas}

1 Nota do Revisor: é importante esclarecer que o conceito integração não assumiu, no contexto italiano, o sentido similar àquele recorrente na literatura especializada brasileira. Durante vários anos integração foi o conceito predominante, mesmo quando era referido um processo de ampla adaptação contextual e de mudanças institucionais para favorecer a presença do aluno com deficiência. Desse modo, os conceitos de integração e inclusão devem ser identificados, no debate proposto pelo presente texto, como similares e contínuos.

2 Para aprofundamento nesta direção recomenda-se o texto de Canevaro (2007), que recolhe contribuições de diversos estudiosos italianos da Educação Especial.

3 D’Alonzo e Ianes (apud) em Canevaro (2007, p. 185-221) discutem os resultados de uma investigação de satisfação da inclusão escolar (Indagine di Soddisfazione dell'Integrazione Scolastica), que podemos chamar de Sistema ISIS, aberto a uma comparação de opiniões de todas as figuras do sistema escolar (dirigente, professores, educadores, famílias, operadores escolares para as deficiências). Veja também, na mesma obra, Crispiani e Giaconi, Indicatori di qualità dell'integrazione scolastica dei disabili, p. 303-323.

4 A tipologia de prevenção primária, secundária e terciária foi introduzida pela primeira vez por Caplan. Ver referência.

5 No caso do autismo encontramos estudos de vários autores (Kanner e Eisenberg, Rutter, Stone, Ozonoff, etc.) sobre a prevalência do distúrbio autista ou de traços comuns à tríade autista (comunicação, interação social e imaginação) ou às funções executivas, geralmente em irmãos gêmeos e não gêmeos (Frombonne, Jorde, Mason e Waldmann).

6 A classificação de uma prevenção universal, seletiva e específica substituiu a tradicional distinção entre prevenções primária, secundária e terciária, de origem médica (Gordon, 1987).

7 No sentido de aplicável a todas as modalidades ou esferas da personalidade, como indicado por Lazarus (1976) e Rovetto (1994).

8 É a posição de modularistas, mentalistas, da abordagem psicoeducativa de Peeters (1999; 2000), de posições cognitivas e neurocognitivas, que aprofundaremos neste artigo.

9 Sobre a teorização do belga Theo Peeters sobre as características qualitativas da percepção e do pensamento no sujeito com autismo.

10 Com o termo "estado mental" nos referimos a estados psíquicos, emoções, imaginações, fingimentos, condutas simbólicas, etc.

11 Frith (1998, p. 197-199; p. 201-203) apresenta diversas experiências para provar a sua hipótese de que crianças autístas não conseguiriam entender os estados 
mentais de outras pessoas. Antes dos três-quatro anos as crianças em geral não conseguem entender as implicações de uma falsa crença, e os experimentos pretendiam demonstrar que os sujeitos com autismo continuam a não entendê-las por mais tempo, além de tal idade mental. Por exemplo, uma experiência com um tubo de Smarties (embalagem em forma de tubo com pequenos chocolates coloridos) servia para provar a sensação de uma falsa crença. "Todas as crianças examinadas esperavam encontrar dentro do tubo chocolates e ficavam frustradas quando encontravam um lápis. Algumas crianças com autismo sabiam que encontrariam um lápis, por já terem sido submetidas ao teste anteriormente. Quando eram questionados sobre o que teria respondido uma criança submetida ao teste pela primeira vez, os sujeitos com autismo respondiam 'um lápis'. Recordavam que haviam respondido que continha chocolates na primeira vez e, mesmo assim, não conseguiam entender porque as outras crianças cometeriam o mesmo erro que eles haviam cometido".

12 ToMM (Theory of Mind Mechanism), sistema modular para a leitura da mente, em Baron-Cohen (1997).

13 Alguns traços do pensamento, como de outras funções, parecem contrastantes entre elas, até constituírem duas condutas exatamente opostas, fenômeno definido como diades funcionais.

14 De Clerq (2006).

15 Hodgdon (2006).

$16 \mathrm{O}$ mesmo pode ser dito da percepção e da linguagem.

17 Com relação ao distúrbio de imaginação, a pesquisa foi implementada pelos estudos sobre os neurônios-espelho. Os autores não deixam de colocar em evidência a centralidade dos neurônios-espelho para interpretar o objetivo das ações percebidas (vistas ou escutadas), seus sentidos, para ser capaz de reproduzi-las. Tal exercício aparece fortemente disturbado na síndrome do autismo, como anteriormente intuído por diversas abordagens teóricas, especialmente cognitivistas e, de modo mais perspicaz, pelos mentalistas com a conhecida fórmula de distúrbio "da teoria da mente". À escassa ou nenhuma atividade dos neurônios espelho, no caso dos sujeitos com autismo, atribui-se o retardo nas aprendizagens imitativas, motoras e linguísticas (Brandi; Bigagli, 2004, p. 153-162).

18 Sinestesia-Concentração, simultaneidade coordenada de ao menos duas ações motoras, perceptivas, sensório-motoras, linguísticas, linguístico-motoras, etc. Função espontânea e organizada que pode apresentar-se também de forma disturbada, por déficit de um componente ou por desordem de coordenação, provocando problemas de coordenação, cognição, de aprendizagem, entre outros. Veja deficit, desordem, dispraxia, decognição, dispercepção, distúrbios de aprendizagem, assinergia (Crispiani; Giaconi, 2008).

19 O menino selvagem (L'enfant sauvage) não era autista, como considerado por alguns, mas acometido de grave afasia, com forte privação ambiental, todavia o trabalho do médico-pedagogo Itard foi realizado com importantes intuições para a adaptação ambiental, material e condução geral do caso (Crispiani, 1998).

20 Para um aprofundamento do programa TEACCH ver Schopler \& Mesibov (1998); Micheli (1999) e Peeters (1999).

21 A escolha de utilizar fotos, desenhos ou palavras é feita com base no nível de simbolização do sujeito autista.

Educação \& Realidade, Porto Alegre, v. 39, n. 3, p. 687-705, jul./set. 2014.

Disponível em: <http://www.ufrgs.br/edu_realidade> 
Organização do Espaço e do Tempo na Inclusão de Sujeitos com Autismo

\section{Referências}

ALIATA, Paolo; UCELLI, Stefania. Adolescenti e Adulti con Autismo: la sessualità possibile. In: AA VV. Bergamo: La Provincia di Bergamo per l'autismo, 2006. P. 255-268.

ALIATA, Paolo. La Sessualità Possibile: adolescenti e adulti con autismo. Autismo e Disturbi dello Sviluppo, Trento, Erickson, v. 4, n. 2, p. 67-85, 2006.

APA - American Psychiatric Association, DSM-IV-TR. Manuale Diagnostico e Statistico dei Disturbi Mentali. Text Revision. Milano: Masson, 2002.

BARON-COHEN, Simon. L'Autismo e la Lettura della Mente. Roma: Astrolabio, 1997.

BARON-COHEN, Simon; HADWIN, Julie; HOWLIN, Patricia. Teoria della Mente e Autismo. Insegnare a Comprendere gli Stati Psichici dell'Altro. Trento: Erickson, 1999.

BARON-COHEN, Simon et al. The Amygdala Theory of Autism. Neuroscience and Biobehavioral Reviews, Elsevier, v. 24, n. 3, p. 355-364, 2000.

BERUMENT, Sibel Karak et al. Autism Screening Questionnaire: diagnostic validity. British Journal of Psychiatry, London, v. 175, n. 5, p. 444-451, 1999.

BRANDI, Luciana; BIGAGLI, Andrea. Neuroni Specchio, Linguaggio e Autismo. Quaderni del Dipartimento di Linguistica, Firenze, Università di Firenze, n. 14, p. 153-162, 2004.

CAMPANINI, Fabiana; PRESTI, Silvia. Mani Abili: dall'integrazione scolastica al progetto di vita. Roma: Carocci, 2005.

CANEVARO,Andrea.AllaRicercaDegliIndicatoridellaQualitàdell'Integrazione. In: IANES, Dario; TORTELLO, Mario (Org.). La Qualità dell'Integrazione Scolastica. Trento: Erickson, 1999. P. 15-35.

CANEVARO, Andrea; IANES, Dario. Buone Prassi di Integrazione Scolastica. Trento: Erickson, 2002.

CANEVARO, Andrea. Autismo, Autismi e Processi Educativi. Difficoltà di Apprendimento, n. 6, p. 97-108, 2000.

CANEVARO, Andrea (Org.). Integrazione Scolastica Degli Alunni con Disabilità. Trento: Erickson, 2007.

CAPLAN, Gerald. Principles of Preventive Psychiatry. Londra: Tavistock, 1964.

CARETTO, Flavia. Affettività e Sessualità nelle Persone con Autismo. Autismo e Disturbi Dello Sviluppo, n. 2, p. 253-266, 2005.

CELLI, Pier Luigi. L'Illusione Manageriale. Bari: Laterza 1997.

COTTINI, Lucio. L'Integrazione Scolastica del Bambino Autistico. Roma: Carocci, 2002.

COTTINI, Lucio. Didattica Speciale ed Integrazione Scolastica. Roma: Carocci, 2004.

CRISPIANI, Piero. Itard e la Pedagogia Clinica. Napoli: Tecnodid, 1998.

CRISPIANI, Piero. Pedagogia Clinica. Bergamo: Junior, 2001.

CRISPIANI, Piero. Lavorare con l'Autismo. Bergamo: Junior, 2002.

CRISPIANI, Piero. Didattica Cognitivista. Roma: Armando, 2004.

CRISPIANI, Piero; GIACONI, Catia. Linguaggio e Movimento: una ri-scoperta. Il Contributo dei Neuroni Specchio. Giornale di Pedagogia, Anno IV, p. 3, 2006. 
CRISPIANI, Piero; GIACONI, Catia. Indicatori di Qualità dell'Integrazione Scolastica dei Disabili. In: CANEVARO, Andrea (Org.). Integrazione Scolastica degli Alunni com Disabilità. Trento: Erickson, 2007. P. 303-323.

CRISPIANI, Piero; GIACONI, Catia. Diogene 2008. Manuale di Diagnostica Pedagogica. Bergamo: Junior, 2008.

CRISPIANI, Piero; GIACONI, Catia. Hermes 2008. Glossario Pedagogico Professionale. Bergamo: Junior, 2007.

CRISPIANI, Piero; GIACONI, Catia. La Sindrome di Jack. Bergamo: Junior, 2008. CRISPIANI, Piero. Pedagogia Clinica della Famiglia con Handicap. Bergamo: Junior, 2008.

D’ALONZO, Luigi. Gli Indicatori di Qualità per una Buona Integrazione. In: SERIO, Nicola; MOLITERNI, Pasquale (Org.). Qualità della Didattica, Qualità dell'Integrazione. Dal dire al fare. Vasto: Edizioni Didattiche Gulliver, 2006. P. 36-44.

D'ALONZO, Luigi; IANES, Dario. L'Integrazione Scolastica dal 1977 al 2007: i primi risultati di una ricerca attraverso lo sguardo delle famiglie. In: CANEVARO, Andrea (Org.). Integrazione Scolastica degli Alunni con Disabilità. Trento: Erickson, 2007. P. 185-221.

DAPRETTO, Mirella et al. Understanding Emotions in Others: mirror neuron dysfunction in children with autism spectrum disorders. Nature Neuroscience, London, v. 9, n. 1, p. 28-30, 2006.

DE CLERQ, Hilde. Il Labirinto dei Dettagli: iperselettività cognitiva nell'autismo. Trento: Erickson, 2006.

FILIPEK, Pauline et al. The Screening and Diagnosis of Autistic Spectrum Disorders. Journal of Autism and Developmental Disorders, New York, v. 29, n. 6, p. 439-484, 1999.

FOMBONNE, Eric. Etudes Épidémiologiques de l'Autisme et des Troubles Apparentés. Prisme, Paris, v. 34, p. 16-23, 2001.

FRITH, Uta. L’Autismo. Spiegazione di un Enigma. Bari; Laterza, 1998.

GIACONI, Catia. Didattica e Stili Cognitivi. Bergamo: Junior, 2004.

HADDON, Mark. Lo Strano Caso del Cane Ucciso a Mezzanotte. Torino: Einaudi, 2003.

HERMELIN, Beate. Bright Splinters of the Mind. A Personal Story of Research with Autistic Savants. London: Jessica Kinsley Publishers, 2001.

HODGDON, Linda. A. Strategie Visive e Comportamenti Problematici. Brescia: Vannini, 2006.

JORDE, Lynn; MASON-BROTHERS, Anne; WALDMANN, Ritvo et al. The UCLA University of Utah Epidemiologic Survey of Autism: genealogical analysis of familiar aggregation. AM J Psychiatry, MedGenet, p. 36; 85-88, 1990.

LAMBIASE, Marco. Autismo e Lobi Frontali. Brescia: Vannini Editrice, 2004.

LASCIOLI, Angelo; MENEGOI, Liliana (Org.). Il Disabile Intellettivo Lavora. Milano: F. Angeli, 2006.

LAWSON, Wendy. Sesso e Sessualità nei Disturbi Autistici. Trento: Erickson, 2006.

LAZARUS, Arnold. Terapia Multimodale del Comportamento. Roma: Armando, 1982.

Educação \& Realidade, Porto Alegre, v. 39, n. 3, p. 687-705, jul./set. 2014. 
Organização do Espaço e do Tempo na Inclusão de Sujeitos com Autismo

MARCELLI, Daniel; BRACONNIER, Alain. Adolescenza e Psicopatologia. Milano: Masson, 2006.

MARCUS, Gary. La Nascita della Mente. Torino: Codice Edizioni, 2004.

MICHELI, Enrico. Autismo, Verso una Migliore Qualità della Vita. Reggio Calabria: Laruffa, 1999.

MONTOBBIO, Eurico; LEPRI, Carlo. Chi Sarei se Potessi Essere: la condizione adulta del disabile mentale. Tirrenia-Pisa: Del Cerro, 2000.

MORGAN, Hugh (Org.). Adulti con Autismo: bisogni, interventi e servizi. Trento: Erickson, 2003.

PEETERS, Theo. Autismo Infantile. Orientamenti teorici e pratica educativa. Roma: Ed. Phoenix, 1999.

PEETERS, Theo. L'Autismo, la Ricerca di un Significato. In: MARTOS, Juan; RIVIÈRE, Angel (Org.). Autismo, Comprensiòn y Explicaciòn Actual. Madrid: Ed. Min. de Trabajo y Assuntos Sociales, 2000. P. 45-75.

RIZZOLATTI, Giacomo; SINIGALLIA, Corrado. So quel che Fai. Il cervello che agisce e ineuroni specchio. Milano: Cortina, 2006.

RIZZOLATTI, Giacomo; FABBRI-DESTRO, Maddalena. The Mirror System and its Role in Social Cognition. Current Opinion in Neurobiology, London, v. 18, n. 2, p. 179-184, 2008.

RIZZOLATTI, Giacomo; VOZZA, Lisa. Nella Mente Degli Altri. Neuroni Specchio e Comportamento Sociale. Bologna: Zanichelli, 2008.

ROVETTO, Francesco. Verso un Approccio Multimodale al Trattamento del Ritardo Mentale. In: CARACCIOLO, Ettore; ROVETTO, Francesco (Org.). Ritardo Mentale. Milano: Franco Angeli, 1994. P. 25-42.

SCHOPLER, Eric; REICHLER, Robert J.; RENNER, Barbara R. The Childhood Autism Rating Scale (CARS) for Diagnostic Screening and Classification of Autism. Los Angeles: Western Psychological Services, 1988.

SCHOPLER, Eric; MESIBOV, Gary B. Apprendimento e Cognizione nell'Autismo. Milano: McGraw-Hill, 1998.

SCHOPLER, Eric. Sindrome di Asperger e Autismo High-functioning. Diagnosi e Interventi. Trento: Erickson, 2001.

SIEGEL, Barry. Early Screening and Diagnosis in Autism Spectrum Disorders: the pervasive developmental disorders screening test (pddst). Nih State of the Science. In: AUTISM, SCREENING AND DIAGNOSIS WORKING CONFERENCE, 1998. P. 30-55.

SINPIA, Società Italiana di Neuropsichiatria della Infanza e dell'Adolescenza. Linee guida per l'Autism. Trento: Erickson, 2005.

SKUSE, David. The Developmental, Dimensional and Diagnostic interview (3di): a novel computerized assessment for autism spectrum disorders. Journal of the American Academy of Child and Adolescent Psychiatry, New Haven, v. 43 , n. 5 , p. $548-558,2004$.

THEORET, Hugo et al. Impaired Motor Facilitation During Action Observation in Individuals with Autism Spectrum Disorder. Current Biology, Cambridge, v. 15, p. 84-85, 2005

VALENTI, Antonella. Autismo. Modelli teorici, principi pedagogici e applicazioni educative. Roma: Monolite, 2008.

VILLALOBOS, Michele E.; MIZUNO, Akiko; DAHL, Branelle C.; KEMMOTSU, Nobuko; MULLER, Ralph-Axel. Reduced functional connectivity between V1 
and inferior frontal cortex associated with Visiomotor Performance in Autism. Neuroimage, Bethesda, n. 25, p. 916-925, 2005.

WILLIAMS, Justin H. G.; WHITEN, Andrew; SUDDENDORF, Thomas; PERRET, David I. Imitation, Mirror Neurons and Autism. Neuroscience and Biobehavioural Review, St. Andrews, University of St. Andrews, n. 25, p. 287-295, 2001.

Catia Giaconi é professora associada da Universidade de Macerata. Nomeada na Sociedade italiana de Pedagogia. Conduz pesquisas sobre inclusão escolar e social. Responsável por projetos europeus sobre a inclusão de pessoas com deficiência na educação superior.

E-mail: catia.giaconi@unimic.it

Maria Beatriz Rodrigues é PhD pelo Institute of Development Studies - IDS, Sussex University (G.B.). Colabora desde 2010 na cátedra de pedagogia e didática especial da Universidade de Macerata (Itália). Pesquisadora do Centro Pedagógico Internazionale PROF (Itália).

E-mail: biarodrigues@hotmail.it 